\title{
Ruptured congenital aneurysm of the sinus of Valsalva with ventricular septal defect
}

\author{
H. ALETRAS, V. O. B J ÖRK, I. C U L L HED, A N D F. INTONTI \\ From the Departments of Internal Medicine and Thoracic Surgery, University Hospital, Uppsala, Sweden
}

Ruptured aneurysms of the aortic sinuses have been known since the early description by Hope in 1839 (Perloff, 1960). However, until the last decade the number of reported cases was small. Although this lesion is rare, an increased awareness of the clinical characteristics has been stimulated by successful surgical treatment in a number of patients.

The incidence of unruptured aneurysms is unknown, since there are no diagnostic symptoms or signs. With the current frequent use of thoracic aortographies, unruptured aneurysms will be fortuitously diagnosed in an increasing number of patients investigated for other cardiovascular disorders (Steinberg and Finby, 1956). A perusal of the available literature gives a total of 70 cases of ruptured aneurysm of the sinus of Valsalva (Sawyers, Adams, and Scott, 1957; Gerbode, Osborn, Johnston, and Kerth, 1961). Using the terminology of Walmsley (1929), about threequarters are localized to the right coronary sinus and one-quarter to the non-coronary sinus. Rarely is the left coronary sinus affected.

The aneurysms are due to a structural defect which can be congenital, syphilitic, or mycotic. This classification is difficult since bacterial endocarditis may cause rupture of a congenital aneurysm. Congenital aneurysm of the sinus of Valsalva was until recently thought to be due to a defective development of the distal bulbar septum. However, Edwards and Burchell (1956) showed the lesion to be a defect between the aortic root and the heart manifested as a failure of union of the elastic media of the aortic wall above with the annulus fibrosus of the aortic valve ring below. The defect may result in a diffuse aneurysm or in a more localized, finger-like diverticulum. The walls will be buttressed only by right atrial or ventricular tissue. When rupture occurs it results in an aortic rightheart communication. Aneurysms from the noncoronary cusp rupture to the right atrium, while those from the right coronary cusp usually com- municate with the outflow tract of the right ventricle, but occasionally with the right atrium, left atrium, left ventricle, pulmonary artery, or pericardium.

Aneurysms from the right coronary sinus are often combined with a defect in the membranous interventricular septum, probably due to the same developmental defect (Jones and Langley, 1949). Coarctation of the aorta has also been reported. There is a striking preponderance in males.

Previously the diagnosis was seldom made before death. Now there are many cases in which the diagnosis was suspected clinically and verified at thoracic aortography. We present such a patient in whom surgical repair was successfully accomplished.

\section{CASE REPORT}

B. A., a 29-year-old textile worker, was admitted to the medical department in 1957.

He was the fifth in a family of six children. No family history of heart disease was obtained and the patient was apparently quite normal and healthy during childhood. A murmur was first noted during a routine examination at the age of 10 years. The patient was otherwise asymptomatic. When 16 to 17 years old he noted palpitations and breathlessness on climbing stairs but did not seek medical advice. On military service he was only allowed to do office work. His symptoms gradually progressed until he was admitted to hospital. Digitalis therapy was started in 1956.

FIRST ADMISSION The pertinent findings on physical examination were bounding peripheral pulses, moderate clubbing, and a continuous murmur and thrill, initially thought to represent a patent ductus arteriosus. The Wassermann reaction, Kline and Meinicke tests were negative.

A chest radiograph showed a large heart and increased pulmonary vascular shadows. The cardiac volume was estimated at $710 \mathrm{ml} . / \mathrm{m}^{2}$ B.S.A. A right heart catheterization (Table I) disclosed a moderate pulmonary hypertension and a left-to-right shunt to the right ventricle, which caused a pulmonary blood flow approximately 
T A B LE I

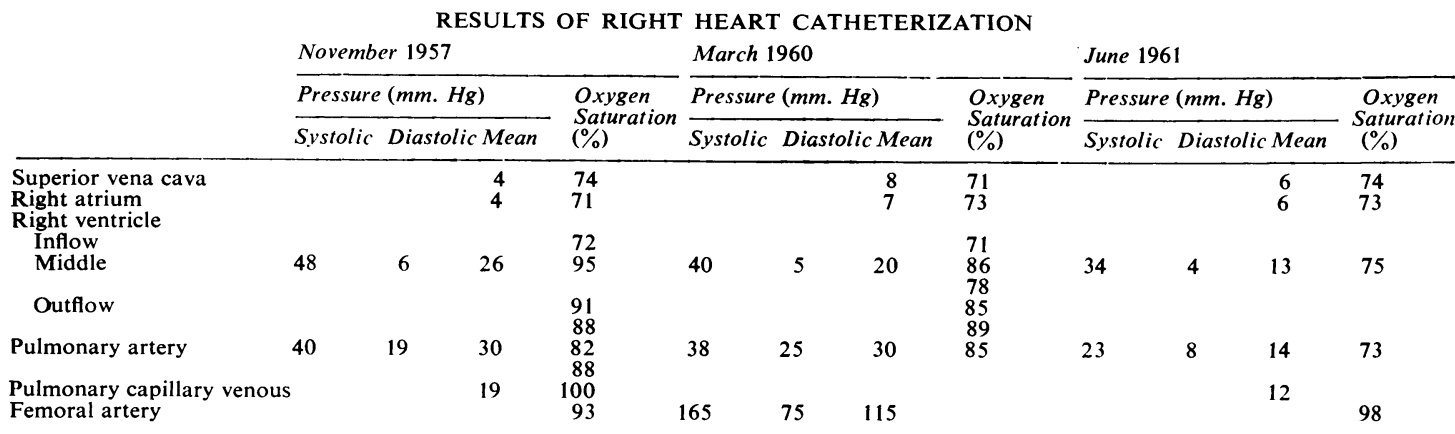

two and a half times that in the systemic circulation. This shunt could not be explained by a ventricular septal defect as the sole lesion because of the character of the murmur.

Thoracic aortography was performed on two occasions with the injection of $70 \mathrm{ml} .76 \%$ urografin in the ascending aorta and rapid exposures in two planes with an automatic film-changer. There was no contrast flow to the pulmonary artery, and in neither instance did we

attain any contrast filling of the proximal ascending aorta.

A ruptured sinus of Valsalva aneurysm was the most probable diagnosis but could not be demonstrated angiographically. As surgical therapy was not possible at that time the patient was discharged. During the following years he worked full time with unchanged symptoms of palpitations and dyspnoea. In 1960 he was re-examined in the medical department.

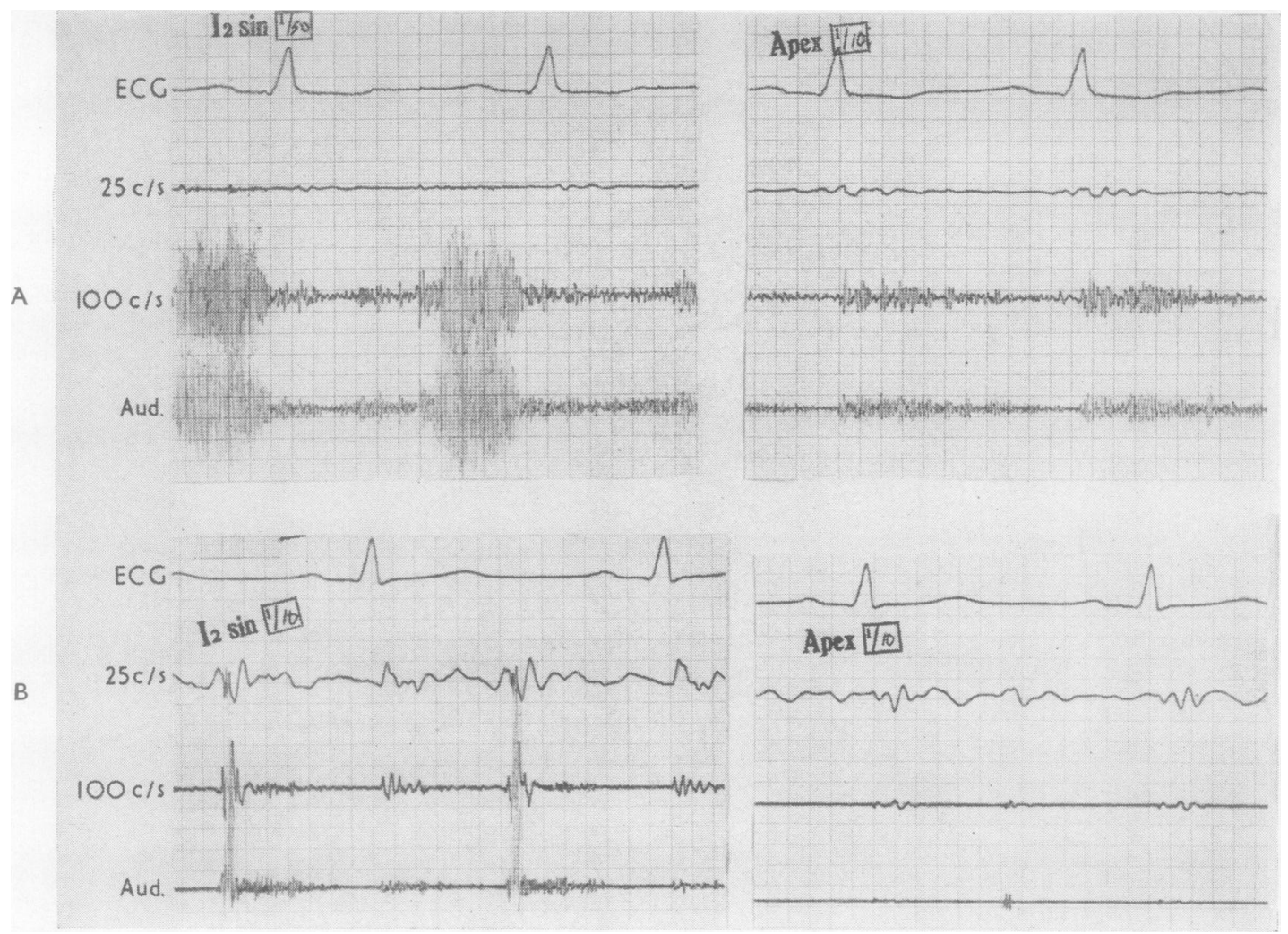

FIf. 1. Phonoccrdiograms from the second left intercostal space and the apex: A, before operation; B, at follow-up. 


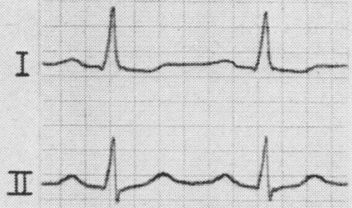

A
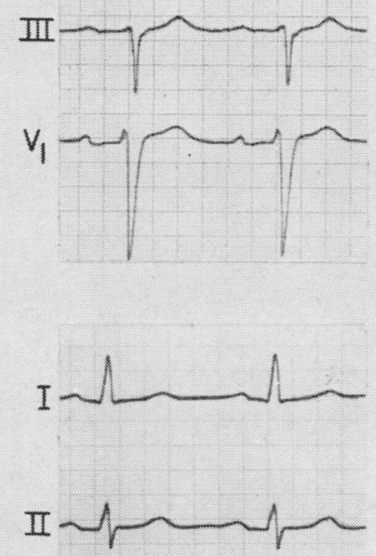

B

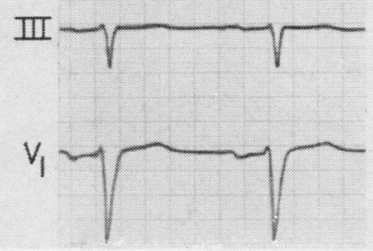

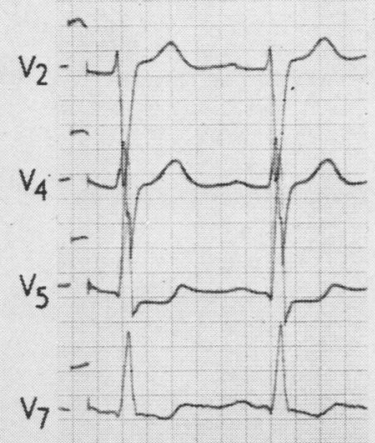
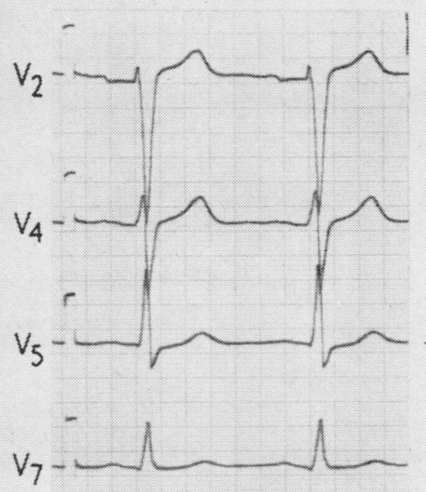

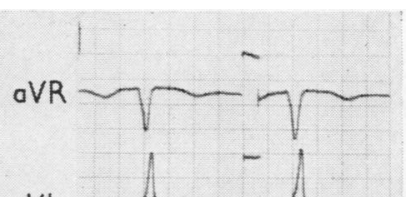

$a V L$

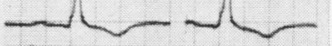

aVF

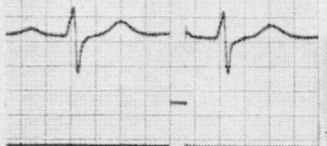

aVR

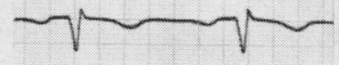

aVL

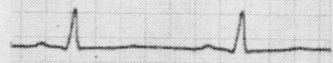

aVF
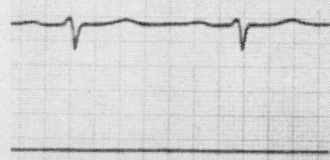

FIG. 2. Electrocardiograms $(A)$ before and $(B) 13$ months after the operation. On both occasions the patier $t$ received the same dose of digoxin, $0.5 \mathrm{mg}$. daily.

SECOND ADMISSION On physical examination his general condition was good. At rest there was slight lip cyanosis but no dyspnoea, no peripheral oedema, and no signs of pulmonary or hepatic congestion. As in 1957, there was clubbing, capillary pulsations, and bounding femoral pulses. The arm blood pressure was $160 / 70 \mathrm{~mm}$. $\mathrm{Hg}$. The venous pressure was estimated at $9 \mathrm{~cm} . \mathrm{H}_{2} \mathrm{O}$ and the arm-to-tongue circulation time at 13 seconds.

A slight praecordial bulging and a distinct continuous thrill were noted. There were increased pulsations suggesting both right and left ventricular hypertrophy. The heart was enlarged both to the right and to the left. A grade 6 continuous murmur was heard over the entire praecordium with maximal intensity over the second left intercostal space in the left sternal border and with systolic transmission to the neck.

The phonocardiogram (Fig. 1A) disclosed normal heart sounds without splitting. The systolic murmur was holosystolic and spindle-shaped. The diastolic murmur showed a high amplitude over the second left intercostal space. It started immediately after the second sound and was diamond-shaped with a maximum in mid-diastole. The electrocardiogram (Fig. 2A) showed slight sinus tachycardia with normal $P$ waves. The ST-T alterations and $\mathrm{QRS}$ voltage suggested left ventricular hypertrophy. A work capacity test with a bicycle ergometer had to be discontinued at a maximum load of $400 \mathrm{kpm} / \mathrm{min}$. because of marked dyspnoea. There was no increased cyanosis during work. A chest radiograph showed a heart size of $800 \mathrm{ml} . / \mathrm{m}^{2}$ B.S.A. (Fig. 3A).

A right heart catheterization was repeated (Table I). The pressures as well as the size and level of the shunt had remained unchanged since 1957. A thoracic aortography with $70 \mathrm{ml} .90 \%$ Hypaque now resulted in a thin contrast filling of the ascending aorta, with early filling of the right ventricular outflow tract and the pulmonary artery. Because of the low density a detailed diagnosis was not possible. It was therefore decided to inject the contrast during acetylcholine-induced cardiac arrest (Björk and Hallén, 1961). After injection of $70 \mathrm{ml} .76 \%$ urografin into the ascending aorta there was an immediate contrast flow from the base of the aorta to the right ventricular 

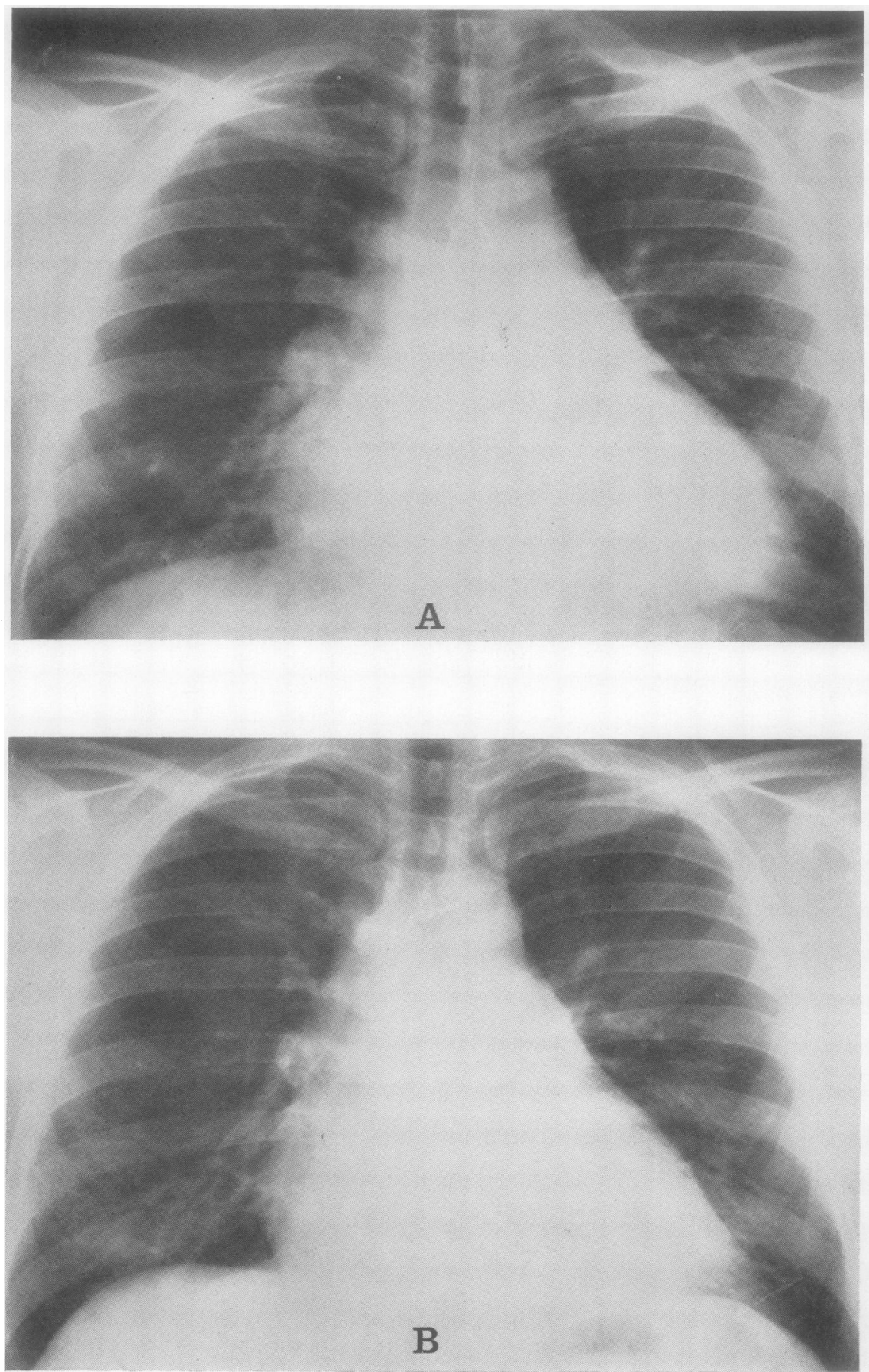

FIG. 3. Chest radiographs in frontal plane (A) before operation, March 1960, and (B) postoperatively, June 1961. Note the decrease in heart size and the less prominent right hilar vessels. 


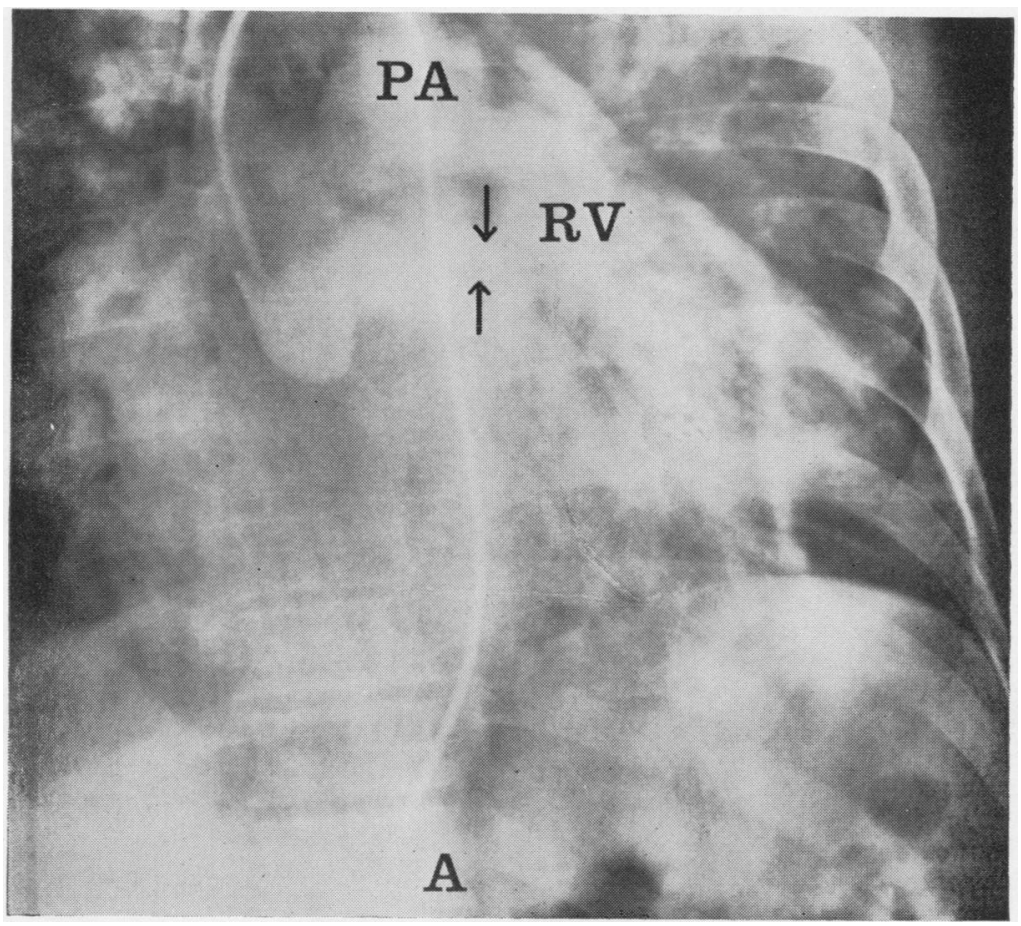

FIG. 4. Pre-operative thoracic aortography during induced cardiac arrest. (A) Frontal plane: The aortic sinuses are contrast filled; arrows indicate site of leakage to right ventricle $(R V) ; P A=$ pulmonary artery. (B) Sagittal plane.

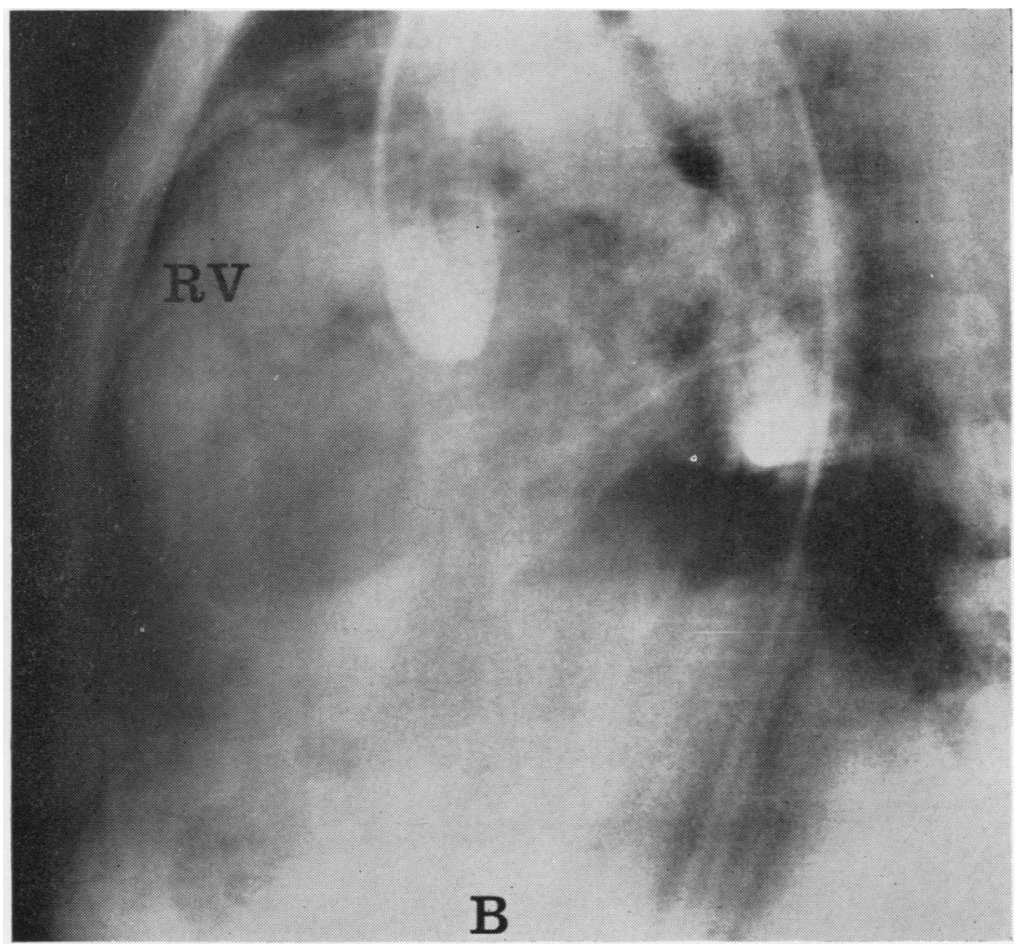


outflow tract (Fig. 4). There were no signs of aortic regurgitation.

The patient was referred for surgical intervention.

Operative findings Operation was performed in May 1960 with the aid of extracorporeal circulation with the spinning disc oxygenator. After median sternotomy a marked thrill was felt over the right ventricular outflow tract. Right ventriculotomy exposed a sinall finger-sized aneurysm originating in the right coronary sinus of Valsalva with two perforations in the wall of the aneurysm. Immediately adjacent to the aneurysm was a $7 \times 3 \mathrm{~mm}$. ventricular septal defect (Figs. 5 and 6). During systole blood was ejected through the ventricular septal defect and during diastole from the ruptured sinus aneurysm. The ventricular septal defect was first repaired by approximation sutures, then the greater part of the aneurysm was excised and the defect closed using one row of interrupted silk sutures. Leakage from the repair sites was not detected after release of the aortic clamp and resumption of the heart action and there was no palpable thrill. The total perfusion time was 37 minutes and the anoxic arrest 30 minutes. Brief intervals of aortic clamp release were allowed to facilitate coronary perfusion.

On microscopical examination the aneurysm wall was seen to be composed of dense collagen tissue with hyalinesclerotic degeneration. Elastin stain showed in several places destruction of the elastic tissue with fragmentation and disappearance of elastic bundles.

The post-operative course was uneventful. The patient was discharged. Three months later he began part-time

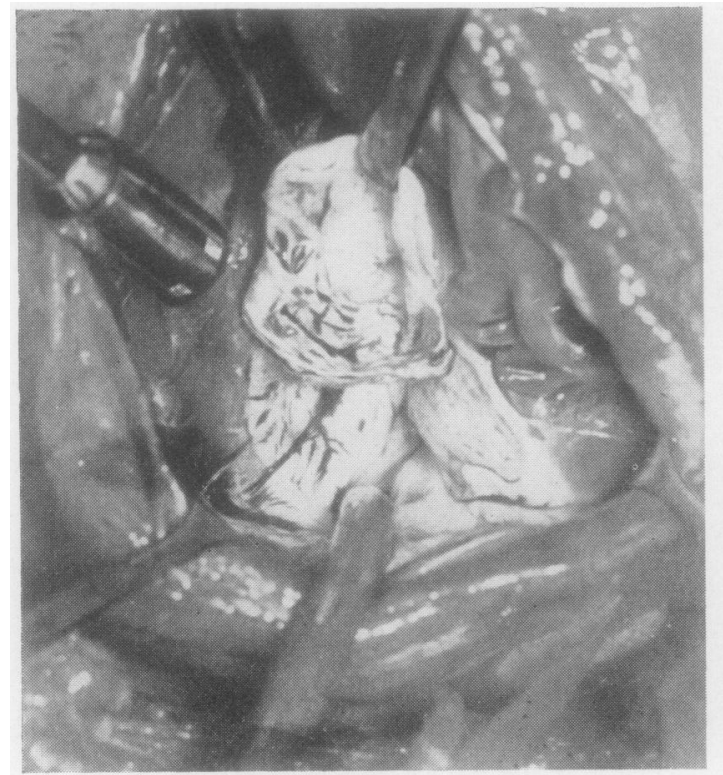

A

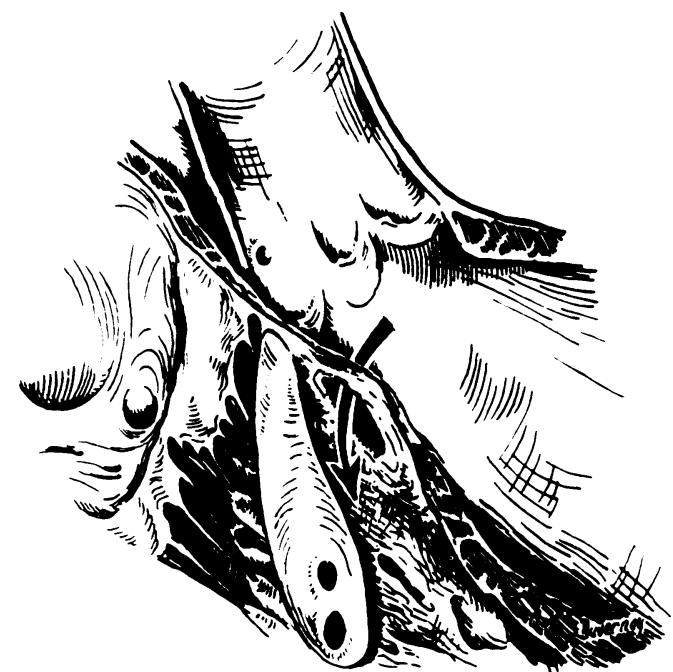

FIG. 5. Diagram of the operative findings. The aneurysm from the right coronary sinus of Valsalva was projecting into the right ventriclt. There were two perforations in the hole of the aneurysm. Adjacent to the aneurysm was a ventricular septal defect (arrow).

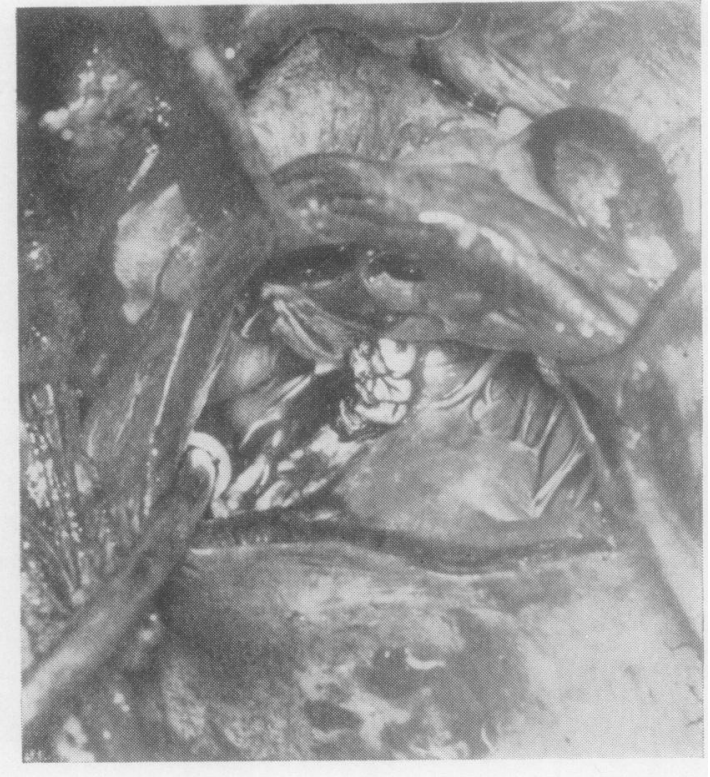

B

FIG. 6. (A) Photograph taken at operation showing the open aneurysm at the top and the ventricular septal defect below. (B) The aneurysm has been excised and sutured and the ventricular septal defect closed by isolated sutures. 


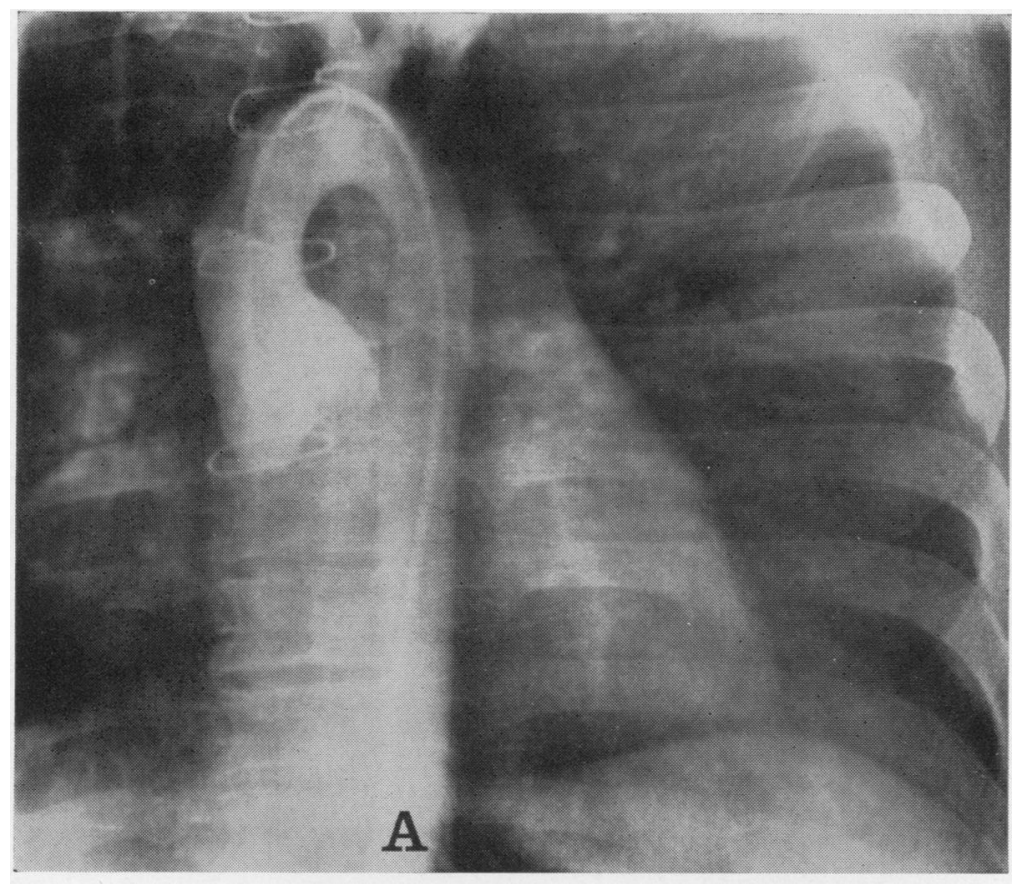

FIG. 7. Post-operative thoracic aortography. (A) Frontal plane: no contrast is visible in the right heart or pulmonary artery. (B) Sagittal plane: arrows indicate subvalvular contrast-flow to the left ventricle during diastole.

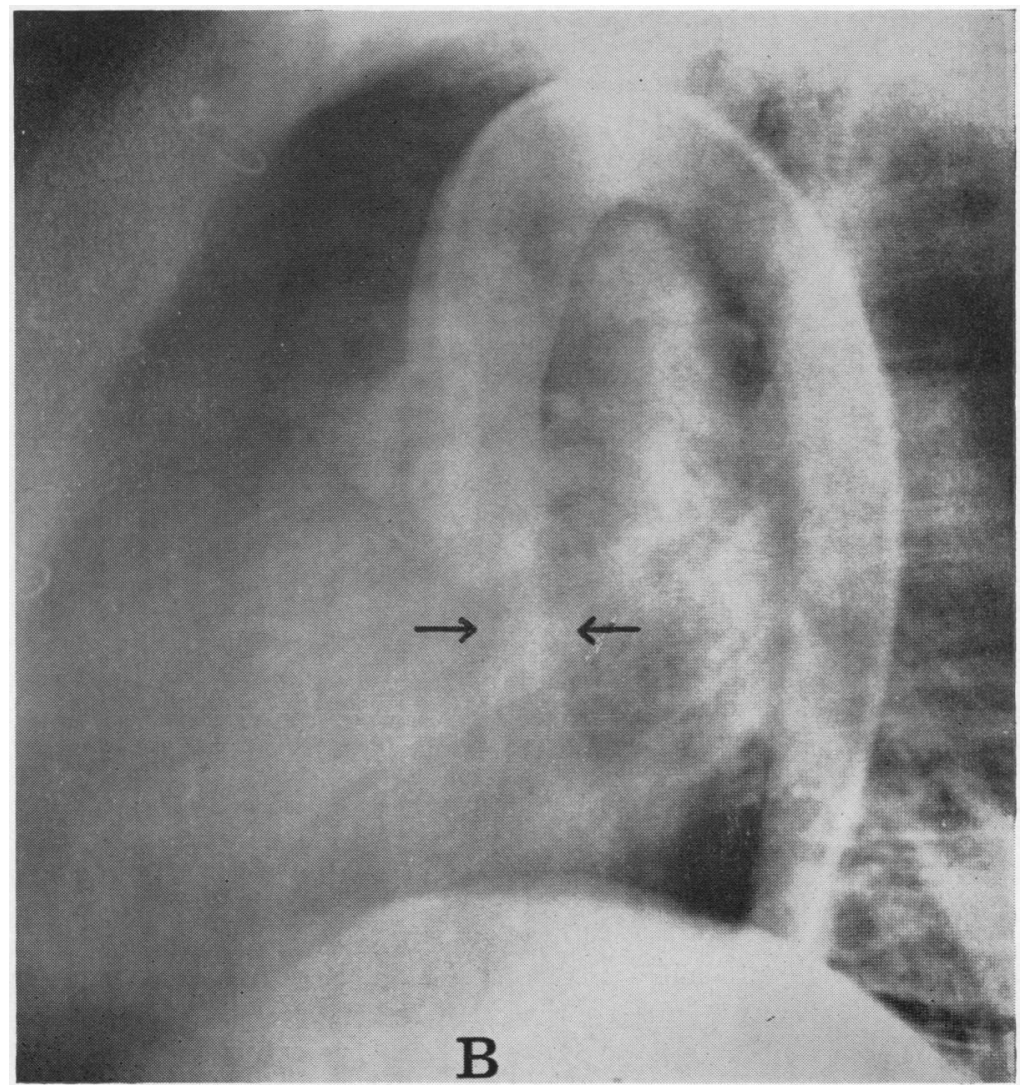


work and after a further six months he resumed fulltime work. The digitalis therapy was continued.

THIRD ADMISSION A follow-up examination was made in June 1961. The patient was then free of symptoms. He had no dyspnoea or palpitations on walking upstairs or climbing hills and there was no cyanosis. His blood pressure was $135 / 85 \mathrm{~mm}$. Hg. No capillary pulsations and no femoral artery tone could be detected. There were no abnormal pulsations and no thrill. The second pulmonary sound was moderately accentuated without splitting. A grade 1 systolic murmur was heard over the left sternal border and the base of the heart without transmission. There was a grade $3 \mathrm{high}$-frequency protodiastolic murmur over the left sternal border.

A phonocardiogram (Fig. 1B) verified the physical findings. The electrocardiogram (Fig. 2B) was normal. The radiological heart size was reduced to $610 \mathrm{ml} . / \mathrm{m} .{ }^{2}$ B.S.A. with normal lung fields (Fig. 3B). The work capacity was found to exceed $800 \mathrm{kpm} / \mathrm{min}$.

On right heart catheterization (Table I) the pressures in the pulmonary circulation were normal and there was no detectable shunt. The cardiac index was $5.621 . / \mathrm{min}$./ $\mathrm{m}^{2}{ }^{2}$ On thoracic aortography $(70 \mathrm{ml} .90 \%$ Hypaque) the ascending aorta became distinctly outlined and there was no contrast flow to the right ventricle or pulmonary artery (Fig. 7). The root of the aorta appeared broad in relation to the ascending aorta and there was a minimal subvalvular contrast leakage in diastole to the left ventricle.

\section{DISCUSSION}

In our case a syphilitic or mycotic aetiology of the aneurysm can be excluded by the negative seroreactions, the history, and the co-existence of another heart malformation.

A diagnosis of a ruptured congenital aneurysm of the sinus of Valsalva is in most cases suggested by the history when there is a sudden onset of dyspnoea, palpitations, chest pain, and right heart failure in a previously healthy young patient. On physical examination one finds a machinery-like murmur. The same clinical picture may result from rupture of an aortic aneurysm into the pulmonary artery or superior vena cava: this lesion is usually rapidly fatal. A ruptured aortic leaflet has the same sudden onset but the murmur is more to-and-fro than continuous, and left ventricular failure will dominate the picture.

Rupture occurs most frequently in the second or third decade, but is described in early infancy (Davidsen, Fabricius, and Husfeldt, 1958; Kjellberg, Mannheimer, Rudhe, and Jonsson, 1959). A strain with a Valsalva manoeuvre may precede rupture (Davidsen et al., 1958; Lippschutz and Wood, 1960).

In our case the history gave no clue as to the time of rupture. The murmur heard at 10 years of age could have been due to the ventricular septal defect. The patient experienced symptoms on effort $\stackrel{\vec{\rho}}{\vec{\rho}}$ when 16 to 17 years old but there was no dramatic $\frac{\overrightarrow{0}}{0}$ onset. Similar cases have been reported both in $\frac{C}{0}$ infants and in adults. They have had an insidious onset of symptoms and presented with a continuous murmur. This may have its maximal intensity in

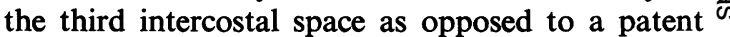
ductus. When a rupture into the right atrium has occurred the murmur may best be heard to the right of the sternum. Evans and co-workers have stated that in aneurysms communicating with the right ventricle the murmur has its greatest amplitude in diastole (Evans, Harris, and Brody, 1961), while $\overrightarrow{0}$ in continuous murmurs of other aetiology the maximum is usually about the second heart sound. $\vec{v}$

On right heart catheterization a left-to-right 0 shunt to the right ventricle exists. This shunt and the character of the murmur may be due to aortic regurgitation with a ventricular septal defect, a patent ductus, or an aortic-pulmonary septal defect with pulmonary regurgitation, a ruptured sinus of $\oplus$ Valsalva aneurysm, or a coronary artery/right heart $\omega$ fistula. In the last-mentioned disorder the murmur is continuous but may have the same maximal intensity in diastole when the right ventricle is involved (Evans et al., 1961). In this group the diagnosis is impossible without thoracic aortography $\mathbb{D}$ or direct catheterization of the fistula (Kjellberg et al., 1959; Lippschutz and Wood, 1960).

Because of the large blood flow there will, in long-standing cases, be dilatation and hypertrophy of all heart chambers and the pulmonary vessels; but with a normal or small aorta. In accordance with this, the findings at chest radiography and electrocardiography are unspecific. The rapid reflux $\dot{0}$ from the aortic root causes the high peripheral $\underline{3}$ pulse pressure with resulting physical signs. The $\delta$ difficulty in obtaining contrast filling of the proximal part of the ascending aorta in our case may be due 0 to the same factor. The same experience has been reported by other authors (Brofman and Elder, 을 1957).

When rupture occurs insidiously, this can be well $\mathcal{\sigma}$ tolerated for many years. On the other hand, when $N$ rupture occurs suddenly, the prognosis is grave. N The mean survival time has been reported to vary 0 from one year (Sawyers et al., 1957) to four and a half years (Gerbode et al., 1961). Davidsen and $\underset{\varnothing}{\complement}$ co-workers (1958) found survival times from one $\stackrel{9}{\sim}$ hour to 17 years. Death usually has been due to heart failure or bacterial endocarditis, although heart block has been described in some cases $\overrightarrow{\mathbb{D}}$ (Micks, 1940; Duras, 1944). Aortic regurgitation $\overrightarrow{\mathbb{D}}$ may occur, probably secondary to inadequate $\frac{\varrho}{\sigma}$ valvular support adjacent to the site of aneurysm formation (Davidsen et al., 1958). In our case there 
were no signs of aortic regurgitation before operation, although this cannot be excluded. The regurgitation found afterwards could possibly have resulted from stretching or shortening of the right coronary sinus, resulting in interference with valve closure.

During the last five years there have been several reports of successful surgical treatment of ruptured congenital aneurysms of the sinus of Valsalva. Reviewing the literature, we found 23 such cases. In six of these a co-existing ventricular septal defect was also repaired (Table II).

\section{T A B LE II}

SUCCESSFULLY REPAIRED RUPTURED ANEURYSMS OF THE SINUS OF VALSALVA, ALONE OR IN COMBINATION WITH A VENTRICULAR SEPTAL DEFECT

\section{Authors}

Lillehei, Stanley, and Varco (1957)

Morrow, Baker, Hanson, and Mattingly (1957)

Cooley (1957)

Dubost, Blondeau. and Piwnica (1958)

Bigelow and Barnes (1959)

Kay, Anderson, Lewis, and Reinberg (1959)

Lippschutz and Wood (1960)

Spencer, Blake, and Bahnson (1960)

Gerbode et al. (1961)

Evans et al. (1961)

Szweda and Drake (1962)

Michaud, Pont, Saubier, Viard, and Termet (1961)

McGoon, Edwards, and Kirklin (1958)

Kuzuya, Tanabe, Kurihara, and Kuramoto (1960)

Gerbode et al. (1961)

Peräsalo, Halonen, Telivuo. Pyörälä, Louhimo, and

Merikallio (1961)
Therkelsen, Fabricius, and Davidsen (1961)

\begin{tabular}{c} 
No. of Cases \\
\hline 3 \\
1 \\
1 \\
1 \\
2 \\
1 \\
1 \\
2 \\
1 \\
1 \\
2 \\
1 \\
1 \\
1 (with V.S.D.) \\
(with V.S.D.) \\
(with V.S.D.) \\
1 (with V.S.D.) \\
1 (with V.S.D.)
\end{tabular}

\section{SUMMARY}

A case of ruptured congenital sinus of Valsalva aneurysm is presented. It occurred in a young man presenting with a continuous murmur and with a history of insidious onset of cardiac symptoms. The correct diagnosis was suspected clinically, but could not be substantiated anatomically until a fourth thoracic aortography was performed in induced heart arrest. At operation with extracorporeal circulation repair was accomplished of the ruptured aneurysm as well as of a ventricular septal defect found at operation. At follow-up with heart catheterization and aortography one year later no shunt could be demonstrated.

A short review is given of the aetiology, anatomy, clinical history, and differential diagnosis. As the prognosis is grave, because of the risks of bacterial endocarditis and heart failure, these cases should be treated surgically.

\section{REFERENCES}

Bigelow, W. G., and Barnes, W. T. (1959). Ann. Surg., 150, 117. Björk, L., and Hallén, A. (1961). J. thorac. cardiovasc. Surg., $2,9$.

Brofman, B. L., and Elder, J. C. (1957). Circulation, 16, 77.

Cooley, D. A. (1957). Discussion of paper by Sawyers et al. (1957).

Davidsen, H. G., Fabricius, J., and Husfeldt, E. (1958). Acta med. scand., $160,455$.

Dubost, C., Blondeau, P., and Piwnica, A. (1958). J. Chir., 75, 539.

Duras, P. F. (1944;. Brit. Heart J.. 6, 61.

Edwards, J. E., and Burchell, H. B. (1956). Proc. Mxyo Clin., 31, 407.

Evans, J. W., Harris, T. R., and Brody, D. A. (1961). Amer. Heart J., 61, 408.'

Gerbode, F., Osborn, J. J., Johnston, J. B., and Kerth, W. J. (1961). Amer. J. Surg., 102, 268.

Jones, A. M., and Langley, F. A. (1949). Brit. Heart J., 11, 325.

Kay, J. H., Anderson, R. M., Lewis, R. R., and Reinberg, M. (1959). Circulation, 20, 427.

Kjellberg, S. R., Mannheimer, E., Rudhe, U., and Jonsson, B. (1959). Diagnosis of Congenital Heart Disease, 2nd ed. Year Book Publishers, Chicago.

Kuzuya, T., Tanabe, H., Kurihara, H., and Kuramoto, K. (1960). Jap. Heart J., 1, 239. Lillehei, C. W., Stanley, P., and Varco, R. L. (1957). Ann. Surg., 146,

Lippschutz, E. J., and Wood, L. W. (1960). Amer. J. Med., 28, 859. McGoon, D. C., Edwards, J. E., and Kirklin, J. W. (1958). Ann. Surg., $147,387$.

Michaud, P., Pont, M., Saubier, E., Viard, H., and Termet, H. (1961). Ann. Chir., 15, 49.

Micks, R. H. (1940). Brit. Heart J., 2, 63.

Morrow, A. G., Baker, R. R., Hanson, H. E., and Mattingly, T. W. (1957). Circulation. 16. 533.

Peräsalo, O., Halonen, P., Telivuo, L., Pyörälä, K., Louhimo, I., and Merikallio, E. (1961). Acta chir. scand., 122, 230.

Perloff, J. K. (1960). Amer. Heart J., 59, 318.

Sawyers, J. L., Adams, J. E., and Scott, H. W. (1957). Surgerv, $41,26$. Spencer, F. C., Blake, H. A., and Bahnson, H. T. (1960). Ann. Surg., 152, 963.

Steinberg, I., and Finby, N. (1956). Circulation, 14, 115.

Szweda, J. A., and Drake, E. H. (1962). Ibid., 25, 559.

Therkelsen, F., Fabricius, J., and Davidsen, H. G. (1961). Acta chir. scand., suppl., 283 , p. 129.

Walmsley, T. (1929). Cited by Davidsen et al. (1958). 